\title{
Cardiac diseases in pregnancy: clinical profile and feto-maternal complications
}

\author{
Latika R. Mehta*, Jagruti Shah
}

Department of Obstetrics and Gynecology, GMERS Medical College and Hospital, Gandhinagar, Gujarat, India

Received: 18 August 2017

Accepted: 16 September 2017

\section{*Correspondence:}

Dr. Latika R. Mehta,

E-mail: drlatikamehta@gmail.com

Copyright: (C) the author(s), publisher and licensee Medip Academy. This is an open-access article distributed under the terms of the Creative Commons Attribution Non-Commercial License, which permits unrestricted non-commercial use, distribution, and reproduction in any medium, provided the original work is properly cited.

\begin{abstract}
Background: Pregnancy in woman with heart disease increases the risk of maternal and fetal complications. About $1 \%$ of pregnant women have concomitant cardiac disease. The present research was conducted to study the profile of cardiac diseases in pregnancy and its associated complications.

Methods: A prospective analysis was carried out of 55 pregnancies of women with cardiac disease from at a tertiary care center. Standard Ante-natal care was furnished to all patients subjective to their requirements. Condition of patient during labour as well as the progress of labour was closely monitored. Fetal and maternal outcome after delivery as well as development of any complication was noted and treated accordingly. Data was analyzed using SPSS software ver. 21.0.

Results: In present study, RHD constituted $71 \%$ cases while CHD constitutes $11 \%$ of all cases of heart disease. Other etiologies were dilated cardiomyopathies (DCM) (12.7\%), IHD (3.6\%) and arrhythmias (18\%). Most common anomaly associated with RHD cases was mitral stenosis $(75 \%)$ either isolated or along with other valvular pathologies. Most common CHD was atrial septal defect seen in 4 out of 6 cases. A total of 8 patients (16\%) developed complications of which, 4 had postpartum hemorrhage, 2 developed pulmonary oedema, 1 had arrhythmia and 1 patient developed septic shock and multi organ failure. A total of $74 \%$ babies were healthy while IUGR and intrauterine deaths were seen in $22 \%$ cases and $4 \%$ cases respectively.

Conclusions: Rheumatic heart disease is the predominant type of cardiac disease in pregnancy. Maternal and perinatal outcome can be improved by team approach at tertiary care center. Counselling for contraception and family planning and follow up during subsequent pregnancies is mandatory.
\end{abstract}

Keywords: Cardiac disease, Caesarean section, Maternal outcome, Pregnancy, Rheumatic heart disease

\section{INTRODUCTION}

An increased prevalence of cardiovascular disease (CVD) has been found in women of childbearing age. ${ }^{1}$ With the presence of CVD in pregnant women posing a difficult clinical scenario in which the responsibility of the treating physician extends to the unborn fetus.

Profound changes occur in the maternal circulation that have the potential to adversely affect maternal and fetal health, especially in the presence of underlying heart conditions.

Total $0.2 \%$ to $4 \%$ of all pregnancies are complicated by cardiac diseases. ${ }^{1}$ In developing countries, rheumatic heart diseases (RHD) constitute $56-89 \%$ of the cases and congenital heart diseases (CHD) only 9-19\%.,3

Total 2.7 deaths per 1000 pregnancies are reported in pregnancies complicated by cardiac diseases. ${ }^{4}$ 
Despite the increased workload of the heart during gestation and labour, the healthy woman has no impairment of cardiac reserve. ${ }^{5}$ In contrast, for the pregnant women with heart disease and low cardiac reserve, the increase in the work of the heart may cause ventricular failure and pulmonary edema. ${ }^{5}$ The presence of heart disease increases the risk of obstetric complication such as preterm delivery, postpartum haemorrhage; pre-eclampsia, increased the risk of cardiac de-compensation and death. ${ }^{6}$ Also there is increased risk of infection, miscarriage, and congenital heart disease. ${ }^{7-9}$

There are relatively fewer studies from Indian subcontinent regarding profile of cardiac diseases in pregnancy and their associated complications. The present study was thus conducted to fill this lacunae in literature.

\section{METHODS}

This is a prospective analytical study of maternal and fetal outcome in 55 cases of heart disease which was carried out in the department of Obstetrics and Gynecology in a tertiary care institute.

\section{Exclusion criteria}

- Patients registered in OPD/ IPD of our hospital.

- Known case of rheumatic heart disease or diagnosed during present pregnancy.

- Patients with congenital heart disease.

- Patients with prosthetic heart valves and surgically corrected heart disease.

- Patients with ischemic heart disease.

Following details were collected for every patients in a pre-designed, structured questionnaire:

- Detailed history with great concern to cardinal cardiovascular symptoms was taken.

- General and systemic examination especially CVS done by senior consultant and cardiologist.

- Suspected cases were confirmed by ECG, 2D- Echo and consultation with physician and cardiologist.

- Obstetrical examination to know the exact gestational age and accordingly antenatal care and management of pregnancy, labour and puerperium.

- Patients with mild heart were called for regular and frequent antenatal check-up and treated conservatively.

- Patients with severe heart disease, who came in OPD or were referred from outside were admitted. They were treated vigorously with consultation of physician and cardiologist.

- Assessment of fetal well-being was done by NST, USG and if needed colour Doppler.

- If there were any sign or symptoms of jeopardy, specific intervention was done.
- Condition of patient during labour as well as the progress of labour was closely monitored. Fetal and maternal outcome after delivery as well as development of any complication was noted and treated accordingly.

- Postpartum patient and baby were monitored in ward, treated as required and discharged when stable. Patients were advised regular follow up and contraception.

\section{RESULTS}

In present study, RHD constituted $71 \%$ cases while CHD constitutes $11 \%$ of all cases of heart disease. Other etiologies were dilated cardiomyopathies (DCM) (12.7\%), IHD (3.6\%) and arrhythmias (18\%) (Table 1).

Table 1: Distribution of patients as per type of cardiac disease.

\begin{tabular}{|lll|}
\hline Cardiac disease & N & Percentage \\
\hline RHD & 39 & 70.9 \\
\hline CHD & 6 & 10.9 \\
\hline DCM & 7 & 12.7 \\
\hline IHD & 2 & 3.6 \\
\hline Arrhythmias & 1 & 1.8 \\
\hline Total & 55 & 100.0 \\
\hline
\end{tabular}

Out of the total 55 cases, $71 \%$ cases knew about their heart disease and $29 \%$ were detected for the first time.

Most common anomaly associated with RHD cases was mitral stenosis $(75 \%)$ either isolated or along with other valvular pathologies. Most common CHD was atrial septa defect seen in 4 out of 6 cases (Table 2 and 3).

Table 2: Distribution of patients as per type valvular pathology associated with RHD.

\begin{tabular}{|lll|}
\hline RHID & N & Percentage \\
\hline MS & 16 & 41.0 \\
\hline MS+MR & 10 & 25.6 \\
\hline MR & 6 & 15.4 \\
\hline MS+AR & 3 & 7.7 \\
\hline MR+TR & 4 & 10.3 \\
\hline Total & 39 & 100.0 \\
\hline
\end{tabular}

Table 3: Distribution of patients as per type of congenital heart disease.

\begin{tabular}{|lll|}
\hline Type of CHID & N & Percentage \\
\hline ASD & 4 & 66.7 \\
\hline PDA & 1 & 16.7 \\
\hline PS & 1 & 16.7 \\
\hline Total & 6 & 100.0 \\
\hline
\end{tabular}

Vaginal and Cesarean delivery was done in 25/55 cases each while MTP was done in remaining 5 cases (Table 4). 
Table 4. Distribution of patients as per mode of delivery.

\begin{tabular}{|lll|}
\hline Mode of delivery & $\mathbf{N}$ & Percentage \\
\hline Vaginal & 25 & 45.5 \\
\hline LSCS & 25 & 45.5 \\
\hline MTP* & 5 & 9.1 \\
\hline Total & 55 & 100.0 \\
\hline
\end{tabular}

*4 in RHD and 1 in CHD

The indications for caesarean were mostly obstetric, only in 2 cases LSCS was done due to patient's cardiac condition. Most common indication for caesarean section was previous section cases followed by severe oligohydramnios. A total of 8 patients developed complications of which, 4 had postpartum hemorrhage, 2 developed pulmonary oedema, 1 had arrhythmia and 1 patient developed septic shock and multi organ failure (Table 5).

Table 5: Distribution of patients as per maternal complications.

\begin{tabular}{|llll|}
$\begin{array}{l}\text { Maternal } \\
\text { complications }\end{array}$ & $\begin{array}{l}\text { RHD } \\
(\mathrm{n}-39)\end{array}$ & $\begin{array}{l}\text { CHID } \\
(\mathrm{n}-6)\end{array}$ & $\begin{array}{l}\text { Others } \\
(\mathrm{n}-10)\end{array}$ \\
\hline CCF & 0 & 0 & 0 \\
\hline Pulmonary edema & 2 & 0 & 0 \\
\hline PPH & 3 & 0 & 1 \\
\hline Arrhythmia & 1 & 0 & 0 \\
\hline Septic shock+MOF & 1 & 0 & 0 \\
\hline Total & 7 & 0 & 1 \\
\hline
\end{tabular}

Pre-term termination of pregnancy was seen in $40 \%$ cases. Fetal outcome in our study is usually good but prematurity is very common, especially in cases of RHD. In our study $74 \%$ babies were healthy while IUGR and intrauterine deaths were seen in $22 \%$ cases and $4 \%$ cases respectively (Table 6).

Table 6: Distribution of patients as per fetal complications.

\begin{tabular}{|lllll|}
\hline $\begin{array}{l}\text { Fetal } \\
\text { complications }\end{array}$ & RHD & CHD & Others & Total \\
\hline None & 10 & 2 & 4 & 16 \\
\hline IUD & 1 & 0 & 1 & 2 \\
\hline IUGR & 7 & 2 & 2 & 11 \\
\hline LBW & 17 & 1 & 3 & 21 \\
\hline Total & 35 & 5 & 10 & 50 \\
\hline
\end{tabular}

\section{DISCUSSION}

Heart disease in pregnancy is an uncommon problem in the developed world but reaches a high prevalence in developing countries. With the advent of more and more modern techniques and advancement in knowledge, the hemodynamic circulation in pregnancy is now better understood and managed. The availability of echocardiography provides information about disease etiology, accurate and noninvasive assessment of severity and means of monitoring progression. Contraindications for pregnancies still remain severe pulmonary artery hypertension, Eisenmenger-syndrome and severe noncorrected cyanotic disease as well. ${ }^{10}$

In developed countries, congenital heart diseases are the commonest cause of cardiopathy in pregnant women. ${ }^{11}$ However rheumatic heart disease still remains the most common cardiopathy found in pregnant woman in our country. In our prospective analytical study conducted over a period of one year, 55 cases of different types of cardiac lesions with pregnancy were included. In $71 \%$ of the patients, heart disease was of rheumatic origin while $11 \%$ of the patients presented with congenital heart disease. Mitral stenosis was the commonest valvulopathy (n-29/39). Our observations were consistent with other previous study. ${ }^{12-14}$ Nayak $\mathrm{RG}$ et al in their study observed $70 \%$ of the patients with heart disease of rheumatic origin and rest $30 \%$ of the patients presented with congenital heart disease. ${ }^{12}$ Shah TM et al observed $69 \%$ of the lesions of rheumatic origin while Yassin K et al observed $60 \%, 26.7 \%$ and $13.3 \%$ was rheumatic heart disease, congenital heart disease and other acquired heart disease respectively. ${ }^{13,14}$ Doshi HU et al. also observed rheumatic cardiac disease $(68.62 \%)$ with mitral valve involvement $(88.57 \%)$ as the commonest cardiac disease in pregnancy. ${ }^{15} \mathrm{Siu}$ et al in their study observed ASD as the commonest congenital heart disease in pregnancy, which is in accordance with our findings. ${ }^{16}$

Cardiac complications were present in $6 \%$ patients $(3 / 50)$. These include pulmonary edema (n-2) and supraventricular tachycardia (n-1). This was similar to the findings of Doshi $\mathrm{HU}$ et al and Nayak RG et al where cardiac complications were observed in $10 \%$ and $13.3 \%$ cases respectively. ${ }^{12,15}$

Termination of pregnancy before 28 weeks occurred in a total of 5 cases. Vaginal delivery occurred in $50 \%$ of the remaining patients (25/50). Rest of the patients underwent LSCS. Indication for performing elective and emergency LSCS were mainly obstetrical. Preterm delivery occurred in $40 \%$ patients while incidence of LBW and IUGR was observed as $42 \%$ and $22 \%$ respectively. Incidence of caesarean delivery as observed by Nayak RG et al was $46.7 \%$ with most of them due to obstetric indications. ${ }^{12}$ Preterm delivery rate was observed as $13.3 \%$. Shah et al observed the LSCS rate as $31 \%$ with incidence of IUGR as $17 \% .{ }^{13}$ Low birth weight and preterm birth was reported in $36.9 \%$ and $24.6 \%$ patients respectively by Yassin $\mathrm{K}$ et al. ${ }^{14} \mathrm{Siu}$ et al. observed caesarean rate as $79 \%$ and preterm birth occurred in $35 \%$ cases of heart disease.

\section{CONCLUSION}

The management of pregnant woman with heart disease requires a multidisciplinary team for optimal maternal and fetal outcome. Rheumatic valvularheart disease is still the most commonly encountered pathology and 
impose a huge burden on limited healthcare resources. Counselling for contraception and family planning and follow up during subsequent pregnancies is mandatory.

Funding: No funding sources

Conflict of interest: None declared

Ethical approval: The study was approved by the Institutional Ethics Committee

\section{REFERENCES}

1. Weiss BM, von Segesser LK, Alon E, Seifert B, Turina MI. Outcome of cardiovascular surgery and pregnancy. Am J Obstet Gynecol. 1998;179(6):164353.

2. Stangl V, Schad J, Gossing G Baumann G, Stangl K. Disease and pregnancy outcome: a single-centre experience. European J Heart Failure. 2008 Sep 1;10(9):855-60.

3. Klein W, Blomstrom-Lundqvist C, de Backer G, Dargie H, Deckers J, Flather M, Hradec J, Mazzotta G, Oto A, Parkhomenko A, Silber S. Expert consensus document on management of cardiovascular diseases during pregnancy. European Heart J. 2003;24:761-81.

4. Bonow RO, Carabello BA, Kanu C, de Leon AC Jr, Faxon DP, Freed MD et al. ACC/AHA 2006 guidelines for the management of patients with valvular heart disease: a report of the American College of Cardiology/American Heart Association Task Force on Practice Guidelines (writing committee to revise the 1998 Guidelines for the Management of Patients With Valvular Heart Disease): developed in collaboration with the Society of Cardiovascular Anesthesiologists: endorsed by the Society for Cardiovascular Angiography and Interventions and the Society of Thoracic Surgeons. Circulation. 2006 Aug 1;114(5):e84-231.

5. Ouyang DW, Khairy P, Fernandes SM, Landzberg MJ, Economy KE. Obstetric outcomes in pregnant women with congenital heart disease. Int J Cardiol. 2010 Oct 8;144(2):195-9.

6. Siu SC, Sermer M, Colman JM, Alvarez AN, Mercier LA, Morton BC et al. Prospective multicenter study of pregnancy outcomes in women with heart disease. Circulation. 2001 Jul 31;104(5):515-21.

7. Bhatla N, Lal S, Behera G, Kriplani A, Mittal S, Agarwal N, Talwar KK. Cardiac disease in pregnancy. Int J Gynecol Obstet. 2003 Aug $1 ; 82(2): 153-9$.

8. Siu SC, Colman JM, Sorensen S, Smallhorn JF, Farine D, Amankwah KS, Spears JC, Sermer M. Adverse neonatal and cardiac outcomes are more common in pregnant women with cardiac disease. Circulation. 2002 May 7;105(18):2179-84.

9. Romano- Zelekha O, Hirsh R, Blieden L, Green MS, Shohat $\mathrm{T}$. The risk for congenital heart defects in offspring of individuals with congenital heart defects. Clini Genet. 2001 May 1;59(5):325-9.

10. Siu S, Chitayat D, Webb G. Pregnancy in women with congenital heart defects: what are the risks? Heart. 1999;81:225-6.

11. Shime J, Mocarski EJ, Hastings D. Congenital heart disease in pregnancy: short- and long-term implications. Am J Obstet Gynecol. 1987;156:313322 .

12. Nayak RG, Patil SK, Laddad MM. Pregnancy with heart disease fetomaternal outcome. Int $\mathrm{J}$ Recent Trends Sci Technol. 2014;11(2):169-172.

13. Shah TM, Mishra K, Ninama P, Parikh C. Cardiac diseases with pregnancy A study of maternal and fetal outcome. IAIM. 2015;2(1):22-29.

14. Yassin K, Elfil AM, Hamid H, Saeed AK, Aziem AA. Epidemiology of cardiac disease during pregnancy in Khartoum Hospital, Sudan. J Women's Health Care. 2015;4(1000227):2167-0420.

15. Doshi HU, Oza HV, Tekani H, Modi K. Cardiac disease in pregnancy-maternal and perinatal outcome. J Indian Med Assoc. 2010;108(5):278-280.

Cite this article as: Mehta LR, Shah J. Cardiac diseases in pregnancy: clinical profile and fetomaternal complications. Int J Reprod Contracept Obstet Gynecol 2017;6:4934-7. 